\title{
Pengembangan Sistem Sampling Air untuk Mengatasi Gangguan Lumpur pada Sistem Online Monitoring Kualitas Air Sungai
}

\section{Development of Water Sampling System to Overcome Mud Disruption in The Application of Online Monitoring of River Water Quality}

\author{
HERU DWI WAHJONO \\ Pusat Teknologi Lingkungan, Badan Pengkajian dan Penerapan Teknologi \\ Gedung Geostech 820, Kawasan Puspitek Serpong 15314, Indonesia \\ Email: heru.dwi@bppt.go.id
}

\begin{abstract}
High sedimentation and domestic waste that pollute rivers in Indonesia is one of the problems that arise in the application of online water quality monitoring in rivers. This problem can cause a rapid decline in the performance of sensor equipment that can be proven through sensor measurement results and it has shortened the treatment time. To deal with this problem, a water sampling technique is needed on rivers that contain a lot of mud. This study aims to ensure the performance of sensor devices to work optimally, to extend the maintenance time and calibration of the probe device on the sensor. This study developed a direct immersed method of river water sampling and automatic pumping methods by making direct system prototypes and testing of rivers. The results of the tests on the river indicate that the sampling system with the two methods developed can extend sensor maintenance time and produce better data. The sensor treatment period that was initially carried out 2 weeks after immersion, but can be longer between 4 to 6 weeks after immersion.
\end{abstract}

Keywords: river sedimentation, domestic waste, calibration sensor, water sampling system, online monitoring

\begin{abstract}
ABSTRAK
Sedimentasi yang tinggi dan sampah domestik yang mencemari sungai-sungai di Indonesia merupakan salah satu masalah yang muncul pada penerapan pemantauan kualitas air online di sungai. Masalah ini dapat menyebabkan cepat menurunnya kinerja peralatan sensor yang dapat dibuktikan melalui hasil pengukuran sensor dan hal tersebut telah memperpendek waktu perawatannya. Untuk menangani masalah ini diperlukan teknik sampling air pada sungai yang banyak mengandung lumpur. Hal ini bertujuan untuk menjamin kinerja perangkat sensor agar dapat bekerja secara optimal. Selain itu agar dapat memperpanjang waktu perawatan serta kalibrasi perangkat probe pada sensor. Penelitian ini mengembangkan metode sampling air sungai secara langsung (direct immersed) dan metode pemompaan otomatis dengan pembuatan prototipe sistem dan pengujiannya sungai secara langsung. Hasil dari ujicoba di sungai menunjukkan bahwa sistem sampling dengan kedua metode yang dikembangkan dapat memperpanjang waktu perawatan sensor dan menghasilkan data yang lebih baik. Periode perawatan sensor yang semula dilakukan 2 minggu setelah pencelupan dapat menjadi lebih lama antara 4 sampai 6 minggu setelah pencelupan.
\end{abstract}

Kata Kunci : sedimentasi sungai, sampah domestik, kalibrasi probe sensor, sistem sampling air, pemantauan online

\section{PENDAHULUAN}

\subsection{Latar Belakang}

Air, terutama air sungai mempunyai peranan yang sangat strategis dalam kehidupan manusia dan makhluk hidup lainnya. Untuk memberikan informasi status mutu air dapat digunakan metode perhitungan indeks pencemaran air dan metode storet yang memberi bobot terhadap hasil pengukuran kualitas air pada tiga paramater kualitas air fisika, kimia dan biologi yang telah diputuskan oleh Keputusan
Menteri Lingkungan Hidup No. 115 Tahun $2003^{(1)}$.

Hasil evaluasi pencemaran kualitas air dengan metode storet yang dilakukan oleh KLHK menunjukkan peningkatan persentasi titik pantau dengan status tercemar selama 20092013. Kondisi kualitas air sungai pada umumnya berada pada status tercemar berat. Persentasi mutu air tercemar berat selama 2009-2013 memperlihatkan tren peningkatan, yaitu tahun 2009 sebesar $62 \%$ dan meningkat menjadi $80 \%$ di 2013 . 
Data dari BPS menunjukkan bahwa pada tahun 2007 sekitar 3\% rumah tangga di Indonesia menjadikan sungai sebagai sumber air minum dan sumber air baku untuk berbagai kebutuhan lainnya, seperti industri, pertanian dan pembangkit tenaga listrik. Di lain pihak sungai juga menjadi tempat pembuangan limbah domestik sehingga tercemar dan kualitasnya semakin menurun ${ }^{(2)}$.

Dari data status mutu kualitas air setiap tahunnya menunjukkan telah terjadi pencemaran air pada beberapa Daerah Aliran Sungai (DAS) di Indonesia, sehingga diperlukan langkah-langkah nyata oleh Kementerian Lingkungan Hidup dan Kehutanan (KLHK) dalam mengendalikan pencemaran air yang terjadi di beberapa DAS tersebut. Oleh karena itu KLHK sejak tahun 2014 hingga 2019 telah menjalankan program kegiatan pengendalian pencemaran kualitas air melalui penerapan teknologi online monitoring kualitas air menggunakan multiprobe sensor di 15 DAS prioritas. Saat ini telah dipasang 16 lokasi stasiun pemantauan kualitas air sungai dan danau di Indonesia ${ }^{(3)}$.

Dari hasil kajian yang telah dilakukan oleh BPPT dan KLHK dalam kegiatan studi penerapan teknologi pemantauan online di Sungai Ciliwung pada tahun 2014 didapatkan fakta bahwa sungai-sungai utama yang merupakan sungai induk dari daerah aliran sungai prioritas memiliki tingkat sedimentasi yang tinggi ${ }^{(16)}$. Pada bagian tengah aliran sungai biasanya terdapat masukan sampah domestik yang terbawa sampai ke bagian hilir sungai dan pada hilir sungai biasanya terdapat tambahan pencemar dari air limbah domestik, sehingga memperberat kondisi kualitas air di sungai tersebut ${ }^{(4)}$.

Tingginya sedimentasi dengan banyaknya lumpur khususnya pada musim hujan ditambah dengan sampah domestik dapat mengganggu kinerja sistem peralatan telemetri online monitoring kualitas air sungai yang menggunakan multiprobe sensor. Penurunan kinerja multiprobe sensor setelah dilakukan kalibrasi sangat dipengaruhi seberapa banyak lumpur yang menempel pada permukaan probe pada sensor ${ }^{(5)}$. Selain itu lapisan minyak yang menempel pada permukaan lensa atau membran pada probe juga dapat mengurangi keakurasian pengukuran ${ }^{(6)}$. Oleh karena itu perlu dikembangkan teknik sampling air yang efektif, sehingga dapat mengurangi dampak negatif lumpur dan sampah domestik terhadap kinerja peralatan sensor.

Diharapkan sistem sampling air sungai yang dikembangkan memiliki fitur-fitur yang dapat memperpanjang waktu pengoperasian sensor dan mempermudah saat pemeliharaan sensor di lapangan. Gambar berikut adalah contoh kondisi fisik sensor kualitas air yang dicelupkan ke dalam sungai yang memiliki sedimentasi tinggi pada musim hujan dan limbah domestik yang banyak di sungai tercemar.
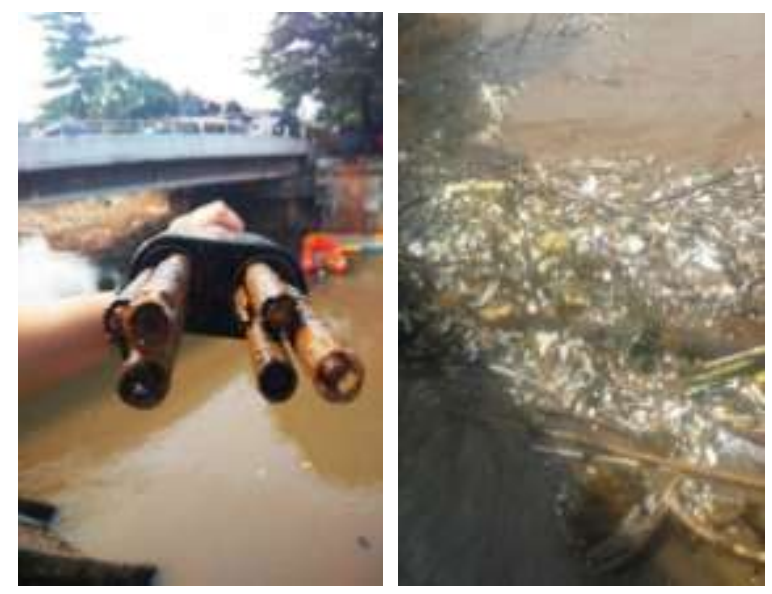

Gambar 1. Kondisi sensor pada sungai tercemar

\subsection{Tujuan Penelitian}

Kegiatan ini bertujuan untuk mengembangkan sistem sampling air yang dapat mendukung sistem online monitoring kualitas air sungai tercemar untuk mengatasi masalah sedimentasi dan sampah domestik agar dapat memperpanjang jangka waktu operasional unit sensor kualitas air dan menjaga kinerja sensor tetap baik.

\section{BAHAN DAN METODE}

Peralatan dan bahan baku yang digunakan dalam mengembangkan sistem pengambilan sampling air sungai ini adalah: pipa pvc, tangki akrilik, meja besi, pompa hisap, timer, contactor, relay, kabel listrik, skun, $M C B$, lampu, saklar kontak, sensor, data logger, alat kerja perpipaan dan kelistrikan. Adapun metode pelaksanaan kegiatan yang akan digunakan untuk mengembangkan sistem pengambilan sampling air pada penerapan sistem online monitoring kualitas air ini adalah sebagai berikut:

- Melakukan kajian literatur terkait sistem sampling air khususnya pada sistem pemantauan kualitas air online menggunakan multiprobe sensor.

- Merancang perangkat keras yang dibutuhkan untuk sistem sampling sesuai dengan sistem telemetri yang ada dan sudah diterapkan.

- Mengembangkan metode pengoperasian sistem sampling air otomatis yang terintegrasi dengan sistem data logger.

- Pembuatan dan perakitan komponen sistem pengambilan sampling yang terdiri dari sistem perpipaan dan panel pengendali otomatis. 
- Pengujian peralatan sistem pengambilan sampling air di sungai selama 30 hari pada bulan Maret 2018.

- Metode sampling air dengan direct immersed tanpa pelampung, direct immersed dengan pelampung dan sistem pompa dipasang pada stasiun pemantauan kualitas air yang ada di Sungai Ciliwung untuk mengetahui perbedaan kinerja sistem sampling yang diujicobakan

\section{HASIL DAN PEMBAHASAN}

\subsection{Kajian Pustaka Teknologi Monitoring}

Kegiatan pengendalian pencemaran kualitas air memerlukan teknologi pemantauan yang sesuai kebutuhan baik secara otomatis maupun manual yang didukung oleh peralatan komputer, baik untuk kegiatan pemrosesan data maupun kegiatan pendistribusiannya. Penerapan teknologi untuk memantau kualitas air secara online adalah sebuah aplikasi yang menggunakan teknologi untuk mengatasi kelemahan pemantauan secara manual. Implementasi sistem ini di lapangan akan dapat mengurangi kelemahan dalam memantau kualitas air sungai secara manual dalam: 1). waktu sebenarnya, 2). Posisi sebenarnya, 3). cepat, 4). Terus menerus selama 24 jam, 5). Bisa mengukur kualitas air sungai secara bersamaan, 6). secara otomatis, dan 7). interaktif $^{(7)}$.

Secara umum berdasarkan cara pemantauannya, kegiatan pemantauan kualitas air dapat dibedakan menjadi dua, yaitu: (a). Pemantauan otomatis menggunakan sistem telemetri dimana pengumpulan dan pemrosesan serta pengiriman data dilakukan secara otomatis, (b). Pemantauan manual dimana pengumpulan data pemantauan dilakukan secara manual oleh operator. Pemantauan secara manual memerlukan SDM yang trampil dalam melakukan pengukuran kadar pencemaran dalam air ${ }^{(8)}$.

Saat ini ada empat metode pemantauan kualitas air yang banyak digunakan, yaitu ${ }^{(9)}$ :

- Metode pengambilan sampel buatan dengan perangkat pendeteksi kualitas air portabel dan pengujian di laboratorium. Metode ini hanya berlaku untuk pemantauan kualitas air sungai dan danau dengan frekuensi sampling mulai dari beberapa kali sehari hingga bulanan.

- Metode pemantauan kualitas air secara otomatis dan kontinyu. Metode pemantauan ini memiliki beberapa stasiun pengamatan dan pusat data. Data dapat ditransfer dari jarak jauh secara otomatis secara real time dari setiap stasiun.
- Metode pemantauan kualitas air dengan teknologi penginderaan jauh, yaitu mendeteksi

spektrum gelombang elektromagnetik yang spesifik (radiasi, refleksi dan hamburan). Data diperoleh dalam bentuk image/gambar yang harus diproses dan diintepretasikan menjadi beberapa parameter kualitas air.

- Metode pemantauan kualitas air menggunakan beberapa organisme akuatik yang sensitif terhadap keberadaan polutan (zat beracun) di dalam air dengan mengukur/ menganalisis perubahan aktivitas organisme yang berbeda di dalam air yang berbeda.

Model pemantuan kualitas air telemetri (tele: jarak jauh, metri: pengukuran) yang ada saat ini berdasarkan metode pengukurannya terdiri dari tiga macam, yaitu ${ }^{(10)}$ :

- Time base telemetri, yaitu pengukuran kualitas air berdasarkan setting waktu yang telah ditentukan. Data logger akan diaktifkan oleh timer yang ada di stasiun pemantauan untuk melakukan pengukuran dan mengirimkan data ke pusat data.

- Polling base telemetri. Metode ini diperuntukkan jika terdapat banyak stasiun monitoring. Setting interval waktu pengukuran dapat dilakukan berdasarkan perintah yang diberikan oleh pusat data.

- Event base telemetri. Metode ini dikembangkan untuk memberikan informasi peringatan dini terhadap perubahan pengukuran parameter kualitas air, sehingga data logger dapat segera mengirimkan data ke pusat data jika terjadi pencemaran air atau kejadian dimana hasil pengukuran telah melebihi baku mutu.

Secara umum arsitektur sistem online monitoring terdiri dari beberapa komponen utama, yaitu: (a). Modul remote terminal unit (RTU) untuk akuisisi data, yang berfungsi untuk mengendalikan proses pengukuran kualitas air dan pengiriman data ke pusat data, (b). Modul sistem sampling dan sensor yang berfungsi untuk melakukan kegiatan sampling air secara otomatis dan mengukur kualitas air pada setiap parameternya, (c). Modul kelistrikan yang berfungsi sebagai sumber listrik bagi seluruh komponen peralatan, yakni sistem kelistrikan solar cell untuk perangkat RTU dan sistem kelistrikan lain untuk perangkat sistem sampling ${ }^{(11)}$.

Saat ini teknologi pemantauan kualitas air online yang biasa disebut sebagai WQMS (water quality monitoring system) banyak menggunakan perangkat multiprobe sensor yang harus diganti probenya dan dikalibrasi menggunakan prosedur standar secara rutin untuk menghilangkan pengotor baik dari alami 
seperti lumpur, limbah domestik maupun biofouling yang dapat menempel pada permukaan sensor untuk menghindari penurunan kinerja sensor. Selain itu pada beberapa kasus dibutuhkan sistem pembersih otomatis (self cleaning) yang mampu membersih-kan sensor secara rutin ${ }^{(12)}$.

\subsection{Sistem Pengambilan Sampling Air}

Teknik pengambilan sampling air pada sistem pemantauan online diperlukan untuk mempermudah pemeliharaan dan menjaga kinerja sensor agar tetap lebih baik. Di beberapa negara sistem sampling diterapkan untuk mengatasi permasalahan yang ada di sungai, misalnya mengatasi lumpur, sampah, minyak atau bongkah-an es di negara bersuhu dingin.

Di negara Serbia penerapan teknologi online monitoring kualitas air di Sungai Kolubara dilakukan dengan menggunakan sistem pompa dan di beberapa lokasi menggunakan sistem celup langsung. Sistem online monitoring yang diterap-kan, merupakan sistem yang menggunakan pompa untuk pengambilan sampel air dari sungai menuju tangki penampung air. Pada tangki penampung tersebut telah terdapat beberapa sensor $(\mathrm{pH}$, Conductivity, Dissolved Oksigen/DO) untuk mengukur kualitas air ${ }^{(13)}$.

Pompa pada sistem tersebut bekerja secara kontinyu 24 jam sehingga stasiun monitoring tersebut harus memiliki suplai listrik yang kontinyu. Tujuan dari penggunaan sistem pompa pada monitoring tersebut adalah untuk menghindari kerusakan sensor oleh bongkahan es pada sungai Kolubara jika sensor dicelupkan secara langsung ke dalam sungai. Gambar berikut merupakan sistem monitoring yang diterapkan di Serbia ${ }^{(13)}$.

Teknik pengambilan sampling air sungai pada sistem online monitoring yang dikembangkan pada penelitian ini lebih disesuaikan dengan kebutuhan penggunaan di sungai-sungai di Indonesia untuk mengurangi dampak sedimentasi lumpur yang tinggi. Metode samplingnya terdiri dari dua, yaitu :

- Metode pengambilan secara langsung, yaitu sensor dicelupkan langsung ke dalam media air sampling secara terapung sekitar 30 50 $\mathrm{cm}$ di bawah permukaan air. Metode ini disebut sebagai sistem pencelupan langsung (direct immersed).

- Metode pengambilan secara tidak langsung, yaitu sensor tidak dicelupkan langsung ke dalam media air sampling, melainkan sampling air yang akan diukur kualitasnya dipompa terlebih dahulu ke dalam sebuah bak penampung kemudian sensor dicelupkan ke dalam bak penampung tersebut. Metode ini disebut sebagai sistem pompa otomatis.

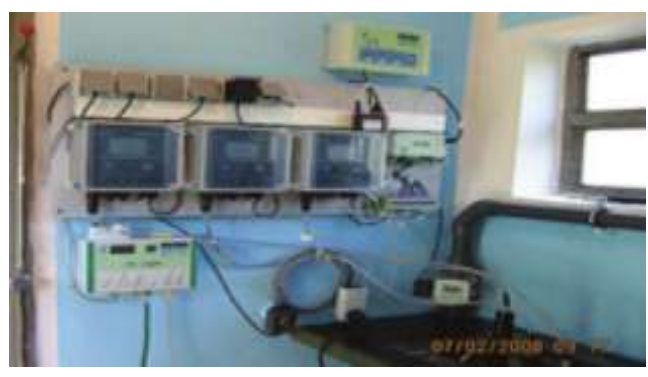

Gambar 2. Sistem monitoring kualitas air di Sungai Kolubara, Serbia

Kedua teknis pengambilan tersebut di atas memiliki keunggulan dan kelemahan masingmasing, diantaranya adalah:

- Pada teknik pengambilan secara langsung, hasil pengukuran merupakan kondisi riil air saat pengukuran dilakukan dan lebih akurat dibanding pengambil secara tidak langsung. Pada teknik pengambilan sampling secara langsung, jika sampling air sangat kotor, sensor dapat cepat tertutup kotoran dan biofouling yang dapat mengakibatkan hasil pengukuran menjadi tidak akurat, sehingga perlu lebih sering dilakukan perawatan dan kalibrasi sensor $^{(14)}$.

- Pada teknik pengambilan sampling secara tidak langsung, hasil pengukuran merupakan kondisi air dimana telah ditampung di dalam bak penampung yang hasilnya dapat berbeda dengan kondisi sebelumnya, sehingga hasil pengukuran dapat lebih sedikit tidak akurat jika dibandingkan dengan teknik pengambilan sampling secara langsung ${ }^{(8)}$. Pada teknik pengambilan sampling secara tidak langsung, sensor relatif lebih bersih karena berada pada posisi yang tertutup dan terjaga dari kotoran sehingga waktu perawatan dan kalibrasi sensor bisa dapat lama ${ }^{(8)}$.

Gambar berikut ini adalah gambar disain sistem untuk kedua metode pengambilan sampling air sungai.

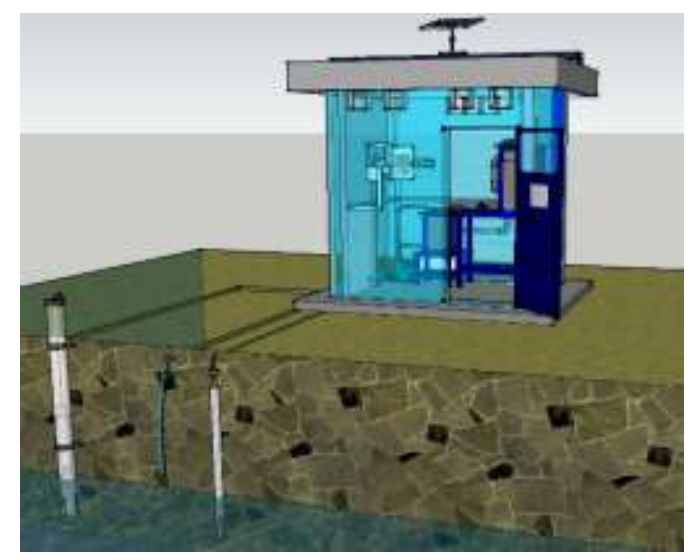

Gambar 3. Disain sistem pengambilan sampling air pada stasiun online monitoring 
Perangkat sistem pengambilan sampling air yang dirancang dan dikembangkan berfungsi untuk pengambilan sampling air sungai secara otomatis sesuai dengan interval waktu yang ditentukan.

\subsubsection{Sistem Pencelupan Langsung}

Pada sistem pencelupan langsung (direct immersed) ini, sensor dicelupkan secara langsung ke dalam sungai melalui pipa pelindung / casing yang terbuat dari bahan PVC yang telah dilubangi sedemikian rupa, sehingga air sungai dapat mengalir masuk ke dalam pipa. Selain itu, agar dapat mengikuti tinggi muka air sungai, sensor diberi pelampung yang juga terbuat dari bahan PVC sehingga dapat naik turun mengikuti tinggi permukaan air. Berikut ini adalah gambar disain dan spesifikasi teknis sistem pencelupan langsung yang diterapkan pada sistem pemantauan kualitas air sungai yang bersedimen tinggi.

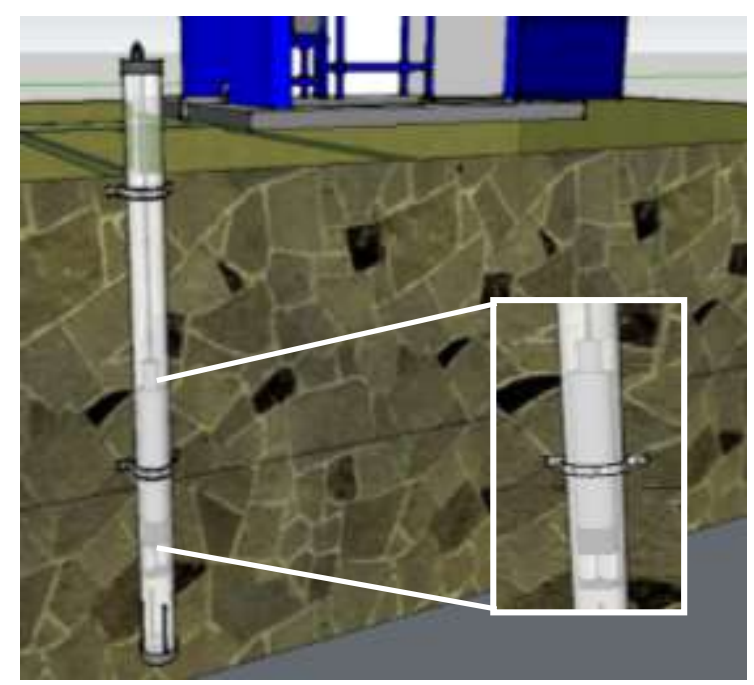

Gambar 4. Disain pipa pelindung sistem pencelupan langsung

Spesifikasi sistem pencelupan langsung :

- Material bahan : PVC

- Diameter pipa : 6" 10"

- Ketebalan pipa : $9 \sim 12 \mathrm{~mm}$

- Panjang standar pipa: $4 \mathrm{~m}$

- Panjang pipa disesuaikan dengan lokasi pemasangan di sungai

- Pipa berlubang pada bagian bawah

- Tipe lubang : garis $(8 \sim 10 \mathrm{~cm}$, lebar 2 3 $\mathrm{mm}$ ) atau lingkaran (diameter $1 \sim 2 \mathrm{~cm}$ )

- Material bahan pelampung : PVC

- Diameter pelampung : 4" 6" disesuaikan dengan diameter pipa casing

- Bahan isi pelampung : styrofoam

- Pengikat pipa : stainless steel (SS) 6" 10"

- Pengikat sensor dan pelampung : kabel slink diameter 3-5 mm, panjang disesuaikan dengan kondisi pemasangan di lapangan
Pelampung sensor dibuat menggunakan pipa PVC dengan diameter lebih kecil dari pipa casingnya. Jika pipa casing menggunakan diameter 8" maka pelampung menggunakan pipa dengan diameter 6". Ke dalam pipa PVC ini dapat diisi bahan pengapung polyurethane/styrofoam yang merupakan bahan insulasi yang memiliki densitas rendah sekitar $40 \mathrm{~kg} / \mathrm{m}^{3(15)}$. Berikut ini adalah contoh gambar disain dan spesifikasi pelampung sensor yang dapat mengampungkan sensor seberat $4 \sim 5 \mathrm{~kg}$.

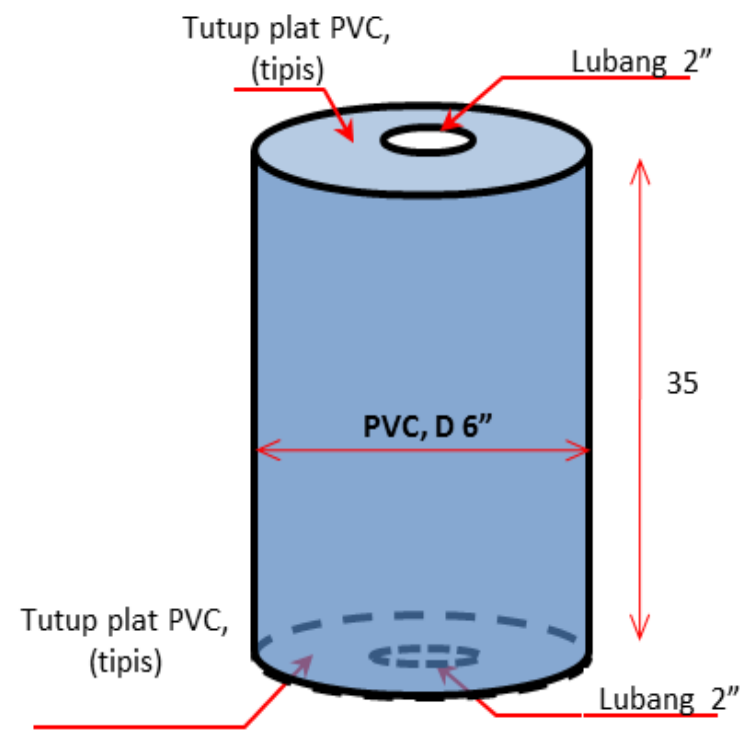

Gambar 5. Disain pelampung sensor

\subsubsection{Sistem Pompa Otomatis}

Pada sistem ini sensor dicelupkan ke dalam tangki yang berisi air sungai dan secara otomatis air sungai dalam tangki tersebut dapat berganti secara rutin dengan menggunakan pompa air. Pompa dapat menyala sesuai interval waktu dan lama pemompaan sesuai setting yang diberikan. Proses pemompaan dikendalikan oleh sistem timer yang diintegrasikan dengan data logger, sehingga dapat menghemat penggunaan energi listrik. Pada sistem pompa juga diperlukan instalasi pipa casing untuk intake pompa di sungai.

Berikut ini adalah spesifikasi teknis dan gambar disain sistem pompa dan pipa intake yang diterapkan dapat pada sistem pemantauan kualitas air sungai.

- Material bahan meja : besi holo/SS holo $2 \sim 3 \mathrm{~cm}$

- Dimensi meja besar : $95 \mathrm{~cm} \times 45 \mathrm{~cm} \times 91 \mathrm{~cm}$

- Dimensi meja kecil : $45 \mathrm{~cm} \times 40 \mathrm{~cm} \times 40 \mathrm{~cm}$

- Material bahan tangki : akrilik $6 \mathrm{~mm}$

- Material bahan frame tangki : besi / ss strip atau besi / ss holo $2 \mathrm{~cm}$

- Dimensi tangki besar : $37 \mathrm{~cm}$ x $37 \mathrm{~cm}$ x 80 $\mathrm{cm}$

- Dimensi tangki kecil : $35 \mathrm{~cm} \times 35 \mathrm{~cm} \times 50 \mathrm{~cm}$ 
- Lubang overflow pada tangki : 1,5" 2"

- Lubang outlet pada tangki : 1" 1,5"

- Jaringan pipa overflow : PVC 1,5" 2"

- Jaringan pipa inlet/output : PVC 1" 1,5"

- Casing pipa intake : PVC 3"

- Filter pangaman : Tosen klep 1" atau 1,5" dari material bahan SS atau kuningan

- Pompa air : 220VAC, 110 watt

- Selenoid valve : 220VAC

- Panel timer control : 220VAC 2 timer

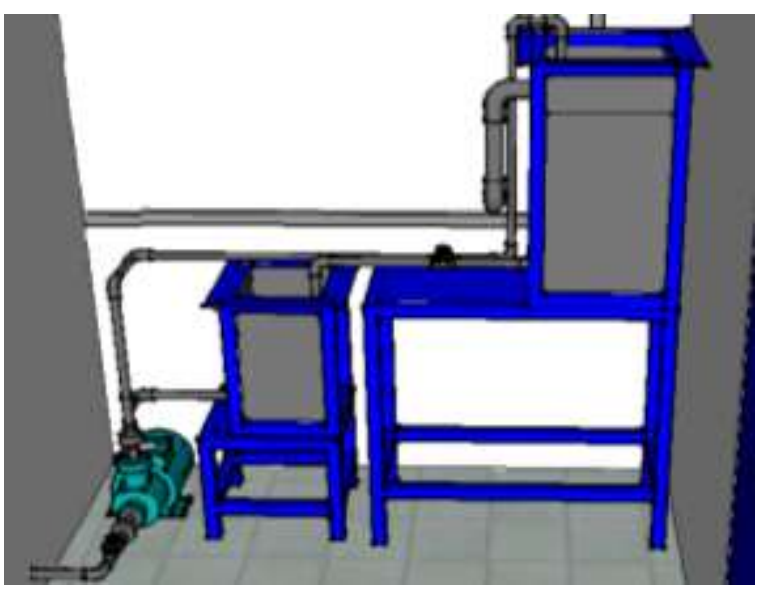

Gambar 6. Disain sistem pompa

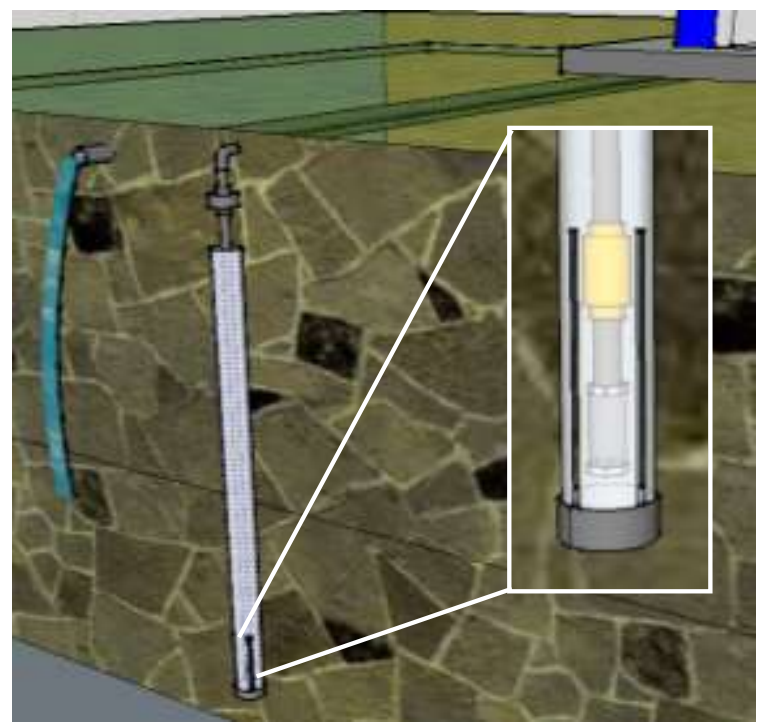

Gambar 7. Disain sistem pipa intake

Kerja sistem pompa dikendalikan oleh timer pada panel control yang diberi trigger oleh perangkat data logger. Gambar berikut ini adalah diagram alir sistem pompa yang terdiri dari beberapa komponen, yaitu : pompa sentrifugal, solenoid valve, tangki air, check valve, dan pipa screen ${ }^{(16)}$.

Dalam sistem pompa terdapat dua buah tangki penampungan. Tangki pertama berfungsi sebagai tempat pengukuran kualitas air sungai. Sensor dipasang di dalam tangki penampungan pertama. Tangki penampungan yang kedua berfungsi sebagai tempat penampungan air yang nantinya akan digunakan untuk mengisi air sebagai pemancing pompa seandainya terdapat kebocoran pada pipa intake. Masing-masing tangki terdapat inlet, outlet, dan overflow. Inlet berada di bagian atas, outlet berada di bagian bawah, dan outlet overflow berada di bagian atas.

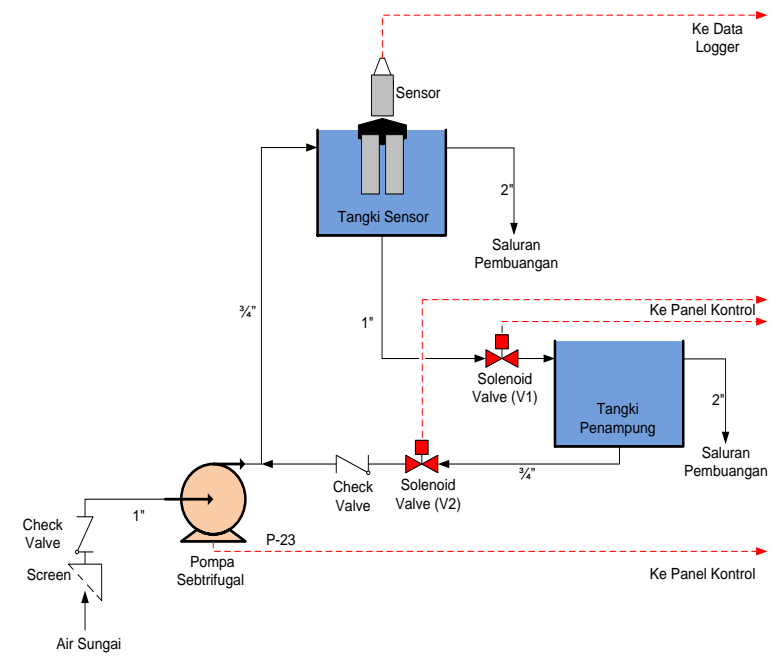

Gambar 8. Diagram alir sistem pompa

Dalam disain sistem ini outlet tangki pertama dialirkan menuju inlet tangki kedua yang alirannya diatur oleh solenoid valve (V1). Outlet tangki kedua dialirkan menuju pompa yang alirannya diatur oleh solenoid valve (V2). Overflow masing masing tangki berfungsi untuk mencegah meluapnya air pada tangki. Cara kerja sistem pompa yang dirancang adalah sebagai berikut :

- Data loger mengirimkan sinyal kepada panel control pompa untuk melakukan pengambilan sampling air.

- Kedua buah solenoid terbuka sehingga air dari tangki pertama mengalir menuju tangki ke dua dan air pada tangki kedua dialirkan untuk mengisi air pada pompa.

- Setelah beberapa menit kemudian pompa akan menyala dan akan mengisi tangki pertama. Jika dilihat pada gambar diagram alir di atas, antara tangki kedua dengan pompa dilengkapi dengan check valve sehingga saat pompa menyala, air tidak akan bisa mengalir menuju tangki kedua.

- Beberapa menit pertama saat pompa menyala, kedua solenoid akan tetap terbuka, hal ini bertujuan untuk menghilangkan air bekas yang sebelumnya yang berada pada pipa. Sehingga air yang berada pada tangki pertama merupa-kan air baru yang diambil secara langsung dari sungai saat itu juga.

- Saat air bekas telah terbuang, solenoid kemudian tertutup sehingga tangki pertama akan terisi air yang baru hingga penuh. 
- Kemudian logger akan memberikan sinyal lagi untuk menghentikan pengambilan sampel air sehingga sistem pemompaan berhenti.

- Setelah beberapa menit sistem pompa berhenti, logger memerintahkan sensor untuk melakukan pengukuran beberapa parameter kualitas air, yaitu: Temp, DO, pH, Salinitas, TDS, Cond, Turbidity, Depth, SwSG, Amonia, Nitrat, dan ORP.

Untuk mengatur cara kerja sistem pompa di atas perlu dibuat sistem panel control pompa dengan wiring diagram seperti gambar berikut ini. Sistem kontrol ini akan dikendalikan oleh data logger dan dengan cara memberikan sinyal 12 VDC ke dalam sistem kontrol. Sinyal 12 VDC ini selanjutnya akan menyalakan kontak relay yang selanjutnya akan menghidupkan sistem kontrol. Kebutuhan kontrol pada sistem ini adalah timer yang berfungsi untuk mengatur kapan pompa akan menyala dan untuk mengatur kapan solenoid valve akan tertutup. Sehingga dibutuhkan 2 (dua) buah timer yakni masing-masing untuk pompa dan untuk solenoid.

Untuk menyalakan pompa dibutuhkan kontaktor sebagai saklar magnetis. Kontaktor ini nantinya akan dikontrol oleh timer pompa. Dalam rancangan ini kerja pompa diatur oleh kontak Normally Open Timer. Solenoid valve merupakan komponen dengan kebutuhan daya yang relatif kecil sehingga dalam rancangan ini solenoid valve langsung dikontrol oleh kontak timer itu sendiri. Dalam rancangan ini solenoid valve diatur oleh kontak Normally Close Timer. Dalam sistem ini diberi pengaman arus berupa MCB yang dipasang pada inline arus ${ }^{(16)}$.

Langkah-langkah kerja sistem kontrol adalah sebagai berikut :

- Data Logger akan mengirimkan sinyal trigger 12 VDC ke relay pada sistem kontrol pompa.

- Selanjutnya relay tersebut akan menghidupkan Timer 1 untuk menyalakan pompa dan Timer 2 untuk menyalakan perangkat solenoid valve secara bersamaan.

- Sesaat setelah relay menghidupkan Timer 2, solenoid akan teraliri listrik (Normally Close) sehingga solenoid akan terbuka, setelah waktu yang ditentukan dalam Timer 2 terpenuhi maka Timer 2 akan memutus arus yang mengalir pada solenoid sehingga solenoid akan kembali tertutup.

- Sesaat setelah relay menghidupkan Timer 1, pompa belum teraliri listrik hingga waktu yang telah ditentukan di dalam Timer 1 (Normally Open). Saat waktu terpenuhi, Timer 1 akan menghidupkan kontaktor sehingga pompa akan teraliri arus.

- Data logger menghentikan sinyal 12 VDC.
- Saat sinyal 12VDC terputus, relay tidak aktif sehingga sistem kontrol pompa akan berhenti.

- Setelah beberapa menit kemudian data logger akan memerintahkan sensor untuk melakukan pengukuran kualitas air pada kondisi dalam tangki sudah tenang.

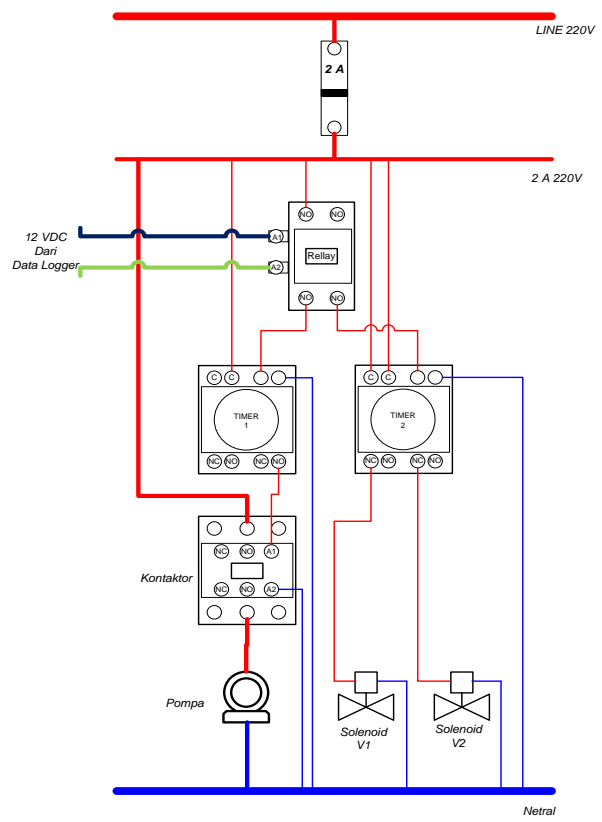

Gambar 9. Wiring diagram sistem kontrol pompa

Penggunaan timer control yang disesuaikan dengan interval waktu pengukuran perangkat data logger dapat menghemat penggunaan daya listrik pompa. Pompa tidak perlu dinyalakan 24 jam, namun hanya beberapa menit saja untuk mengganti air di dalam tangki. Gambar berikut ini adalah time series operasional sistem pompa.

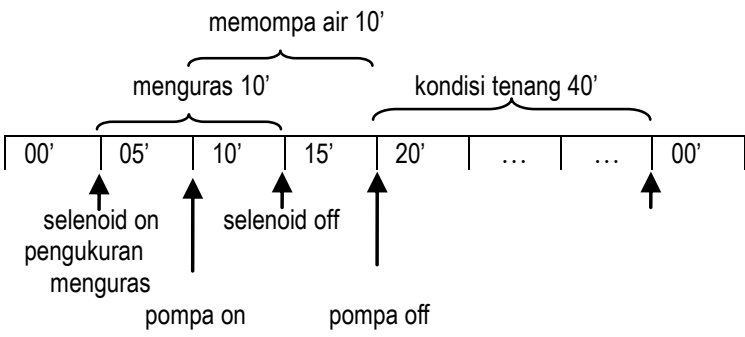

Gambar 10. Time series pengoperasian sistem pompa

Pada gambar time series di atas, jika interval waktu pengukuran kualitas air dilakukan setiap 60 menit sekali pada menit ke 00.00 , maka data logger dapat diset dengan memberikan sinyal trigger kepada panel kontrol pompa pada menit ke 05.00 untuk menyalakan selenoid selama 10 menit hingga menit ke 15:00. Pada menit ke 10:00 pompa dinyalakan selama 10 menit hingga menit ke 20:00 dan data logger memutus sinyal ke panel timer control. Sehingga air dalam tangki dapat kembali tenang selama 40 menit. 


\subsection{Hasil Ujicoba Penerapan}

Ujicoba penerapan sistem sampling air pada sistem online monitoring kualitas air telah dilakukan di sungai Ciliwung selama kurang lebih satu bulan pengamatan. Gambar 11 menunjukkan hasil pengamatan terhadap kebersihan sensor. Secara visual, lumpur yang menempel pada sensor dengan sistem direct immersed selama 2 minggu tanpa pelampung (gambar a) lebih tebal jika dibandingkan dengan sensor pada sistem direct immersed dengan pelampung selama 2 minggu pencelupan (gambar b). Sedangkan sensor yang diterapkan dengan sistem pompa (gambar c) secara visual lebih bersih jika dibandingkan dengan sensor yang diaplikasikan secara direct immersed baik dengan pelampung atau tanpa pelampung. Partikel lumpur yang menempel ke sensor pada sistem pompa lebih halus dan lebih mudah dibersihkan jika dibandingkan dengan sensor pada pencelupan langsung.

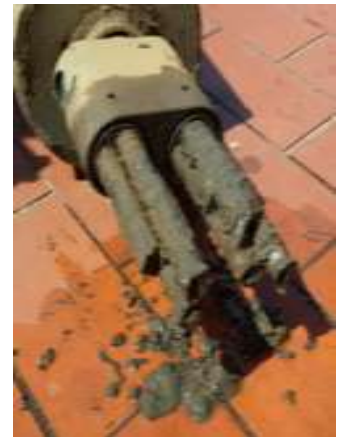

(a)

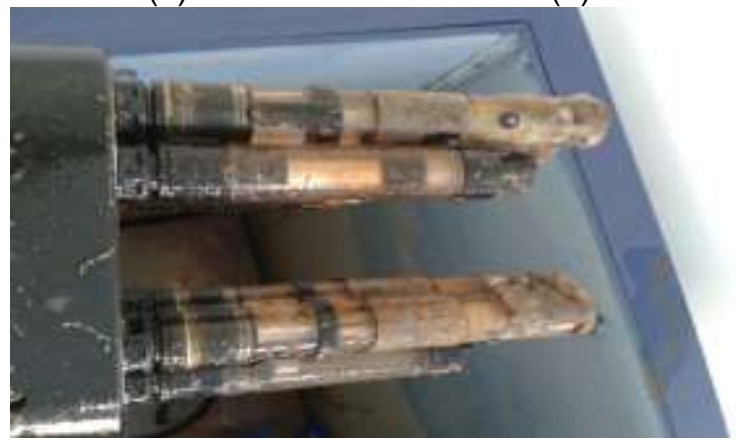

(c)

Keterangan. : (a). direct immersed tanpa pelampung, (b). direct immersed dengan pelampung, (c). sistem pompa

Gambar 11. Perbandingan kondisi lumpur yang menempel di sensor pada sistem sampling dengan kondisi 2 minggu pencelupan.

Pengamatan data dilakukan mengukur kualitas air parameter DO pada bulan Maret 2018 selama 30 hari. Sensor DO merupakan perangkat yang sangat sensitif terhadap pengaruh lumpur dalam air. Dari hasil pengukuran kualitas air pada sistem sampling, data parameter DO pada kedua kondisi pencelupan adalah seperti terlihat pada Gambar 12. Sensor tanpa pelampung menunjukkan data DO yang semakin menurun setelah satu sampai dua minggu pencelupan dengan nilai terkecil 0.0 $\mathrm{mg} / \mathrm{l}$ dibandingkan dengan sensor menggunakan pelampung (terkecil $0.25 \mathrm{mg} / \mathrm{l}$ ) dengan tren perubahan angka hasil pemantauan yang hampir sama. Tutupan lumpur pada permukaan probe sensor diduga dapat menyebabkan berkurangnya kemampuan sensor sehingga nilai oksigen tertinggi diperoleh pada system pompa yang memiliki tempelan lumpur paling tipis jika dibandingkan dengan yang lain (Tabel-1).

Pada data hasil pengukuran sensor DO terdapat beberapa data anomali yang mengukur DO di luar range batas pengukuran (0 8 $\mathrm{mg} / \mathrm{l})$. Data anomali didefinisikan sebagai data hasil pembacaan sensor yang jauh berbeda dengan hasil pembacaan sebelumnya ${ }^{(17)}$. Data anomali pada probe sensor DO dapat disebabkan tertutupnya permukaan membrane DO dengan lemak atau minyak dalam air dan juga bisa disebabkan berkurangnya cairan elektrolit di dalam probe DO. Berikut ini adalah tabel data hasil pengukuran parameter DO tanpa data anomali.

Tabel 1. Data pengukuran DO [mg/l] pada ketiga sistem sampling.

\begin{tabular}{cccc}
\hline Tanggal & $\begin{array}{c}\text { Tanpa } \\
\text { Pelampung }\end{array}$ & $\begin{array}{c}\text { Dengan } \\
\text { Pelampung }\end{array}$ & $\begin{array}{c}\text { Sistem } \\
\text { Pompa }\end{array}$ \\
\hline $2018-03-01$ & 0.02 & 1.24 & 3.51 \\
\hline $2018-03-02$ & 0.01 & 1.47 & 2.77 \\
\hline $2018-03-03$ & 0.01 & 1.35 & 4.18 \\
\hline $2018-03-05$ & 0.01 & 1.28 & 4.85 \\
\hline $2018-03-06$ & 0.90 & 1.24 & 5.03 \\
\hline $2018-03-07$ & 0.61 & 1.31 & 6.05 \\
\hline $2018-03-14$ & 0.01 & 1.22 & 5.09 \\
\hline $2018-03-15$ & 0.01 & 0.81 & 4.64 \\
\hline $2018-03-19$ & 0.01 & 0.23 & 4.53 \\
\hline $2018-03-20$ & 0.00 & 0.24 & 4.71 \\
\hline $2018-03-25$ & 0.00 & 0.41 & 3.87 \\
\hline $2018-03-26$ & 0.23 & 0.25 & 3.22 \\
\hline $2018-03-27$ & 0.01 & 0.26 & 2.34 \\
\hline $2018-03-29$ & 0.00 & 0.27 & 3.92 \\
\hline $2018-03-30$ & 0.00 & 0.28 & 3.22 \\
\hline
\end{tabular}

sumber : onlimo.bppt.go.id 


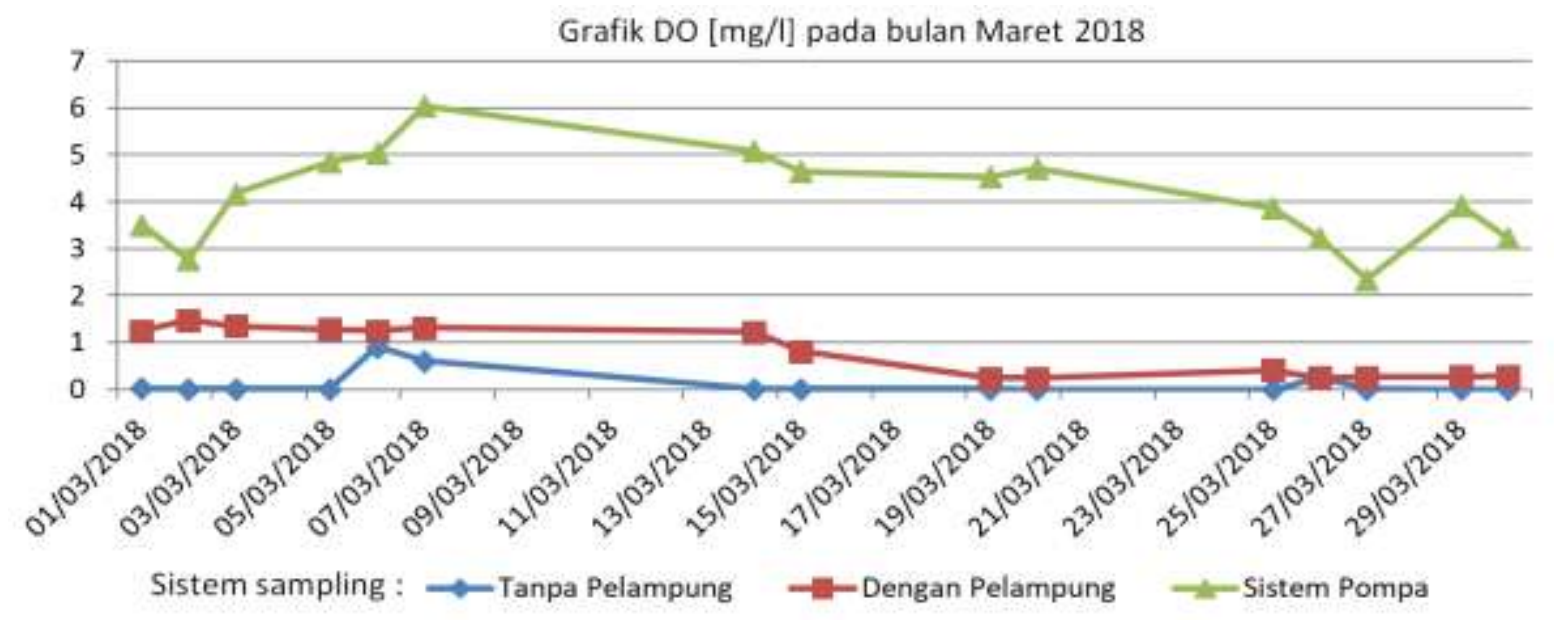

Gambar 12. Perbandingan grafik pemantauan parameter DO pada ketiga sistem sampling

Penggunaan sistem pompa dalam pemantauan kualitas air secara online di Sungai Tisa pada daerah aliran sungai Kolubara di negara Serbia, menunjukkan tren yang sama sepanjang tahunnya. Dalam penelitian yang dilakukan oleh University of Novi Sad, Serbia di Sungai Tisa yang merupakan sungai kelas 1 disimpulkan bahwa walaupun terdapat fluktuasi yang berbeda-beda terhadap hasil pengukuran DO setiap tahunnya, namun pada grafik regresinya menunjukkan hasil pengukuran DO yang stabil (Gambar 13) ${ }^{(18)}$.

DO $\left(\mathrm{mg} \mathrm{dm}^{-3}\right)$

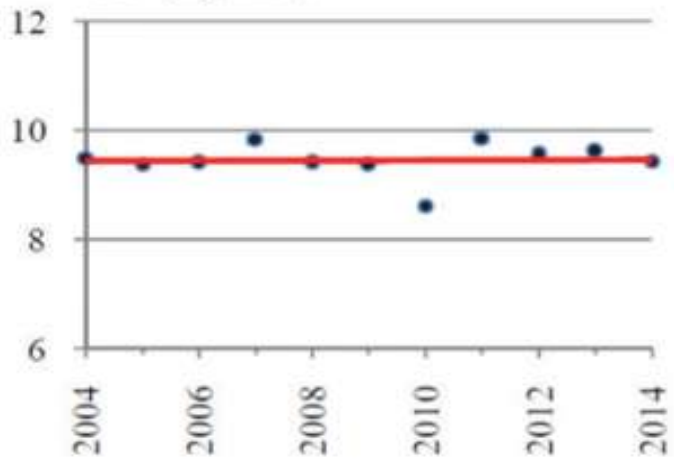

Gambar 13. Grafik rata-rata pengukuran parameter DO di Sungai Tisa, Serbia $^{(18)}$

\section{KESIMPULAN}

Beberapa hal yang dapat disimpulkan dari kegiatan pengembangan sistem sampling air yang digunakan untuk alat online monitoring kualitas air di sungai adalah berikut :

- Untuk mendukung penelitian ini telah dikembangkan dan dibangun sistem sampling air direct immersed tanpa pelampung, direct immersed dengan pelampung dan sistem pompa yang diintegrasikan dengan sistem pemantauan kualitas air online.

- Sistem pelampung sensor yang dapat mengapungkan sensor sekitar $30 \sim 50 \mathrm{~cm}$ di bawah permukaan air sungai dapat bekerja cukup optimal, sehingga dapat mempertahankan kinerja sensor lebih lama karena sensor tidak berada di dasar sungai yang banyak mengandung sedimen / lumpur.

- Penerapan sistem pompa merupakan alternatif solusi yang dapat memberikan keamanan dan kebersihan pada perangkat sensor. Pembuatan tangki air dengan bahan material akrilik dapat memper-mudah operator dalam pemeliharaan peralatan sistem pompa karena dapat terlihat jelas kondisi kebersihan sensor dan air sungai di dalam tangki.

- Hasil ujicoba sistem sampling air sungai menunjukkan bahwa nilai DO pada sistem pompa lebih stabil tinggi dari pada sistem sampling lainnya.

- Penggunaan sistem pompa dapat memberikan hasil yang cukup optimal dalam pemeliharan unit sensor, sehingga dapat mempertahankan kinerja sensor lebih lama dibandingkan jika sensor dicelupkan secara langsung ke dalam sungai tanpa diinstalasikan dengan sistem pelampung sensor.

\section{PERSANTUNAN}

Penulis menyampaikan ucapan terima kasih kepada Direktorat Pengendalian Pencemaran Air (PPA), Ditjen PPKL, Kementerian Lingkungan Hidup dan Kehutanan (KLHK) yang telah bekerjasama dengan Pusat Teknologi Lingkungan (PTL), TPSA, BPPT sejak tahun 2014 hingga saat ini dalam mendukung kegiatan penerapan teknologi online monitoring yang 
telah dikembang-kan oleh BPPT. Terimakasih juga kami sampaikan kepada rekan-rekan Tim Onlimo yang telah membantu dalam melaksanakan kegiatan litbang dan penerapan teknologi online monitoring kualitas air secara online dan realtime di sungai tercemar pada DAS Prioritas di Indonesia.

\section{DAFTAR PUSTAKA}

1. Barokah, G.R., Ariyani, F., \& Siregar, T.H. (2017). Squalen Bulletin of Marine and Fisheries Postharvest and Biotechnology, Vol. 12 Issue 2 : pp 67-74.

2. Ditjen PPKL. (2017). Indeks Kualitas Lingkung-an Hidup Indonesia 2014. Kementerian Lingkungan Hidup dan Kehutanan (KLHK).

3. Direktorat PPA. (2014). Database Penghitung-an Meningkatnya Kualitas Air Sungai di 15 DAS Prioritas. Kementerian Lingkungan Hidup dan Kehutanan (KLHK).

4. Ditjen SDA. (2011). Pengelolaan Sumber Daya Air Menyeluruh \& Terpadu. Jakarta : Direktorat Jenderal Sumber Daya Air, Kementerian PU.

5. Kautsar,M., Isnanto, R. R., \& Widianto, E. D. (2015). Sistem Monitoring Digital Penggunaan dan Kualitas Kekeruahan Air PDAM Berbasis Mikrokontroler ATMega 328 Menggunakan Sensor Aliran Air dan Sensor Fotodiode. Jurnal Teknologi dan Sistem Komputer Vol. 3, No. 1 : pp 79-86.

6. Che, H., Liu, S., \& Smith, K. (2015). Performance Evaluation for a Contamination Detection Method Using Multiple Water Quality Sensors in an Early Warning System. Open Access Water Journal 2015, Vol. 7 : pp 1422-1436.

7. Indriatmoko, R. H. (2017). Perencanaan Sistem Monitoring Kualitas Air Sungai Secara Online. Jurnal Rekayasa Lingkungan, Vol. 10 No. 1 : pp 25-32.

8. Pusyantek. (2015). Laporan Akhir Pemasangan Alat Monitoring Online Sistem Di Sungai Ciliwung dan Sungai Citarum. Jakarta : Pusat Pelayanan Teknologi / BPPT Enjiniring.

9. Jiang, P., Xia, H., He, Z., and Wang, Z. (2009). Design of a Water Environment Monitoring System Based on Wireless
Sensor Networks. Open Access Sensors Journal 2009, Vol. 9 Issue 8 : pp 6411-6434.

10. Mullins, P. (2018). Introduction to Industrial Control Systems - How SCADA Works, URL:

https://www.taitradioacademy.com/lessons/h ow-scada-works/, Tait Radio Academy.

11. Chen, Y., \& Han, D. (2018). Water Quality Monitoring in Smart City-A Pilot Project. Elsevier Vol. 89 May 2018 : pp 307-316.

12. Pillera, O., Deuerleinb, J., Gilberta, D., \& Weberc, J. M. (2015). Installing Fixed Sensors for Double Calibration and Earlywarning Detection Purposes. Elsevier Procedia Engineering Vol. 115 : pp 564-572.

13. Svetomir, M., Bojan, P. (2012). Water Quality Monitoring Automation of Rivers in Serbia. Facta Universitatis, Working and Living Environtmental Protection Vol. 9, No 1, 2012 : pp 1 - 10.

14. Li, T., Winnel, M., Lin, H., Panther, J., Liu, C., O'Halloran, R., Wang, K., An, T., Wong, P.K., Zhang, S., \& Zhao, H. (2017). A Reliable Sewage Quality Abnormal Event Monitoring System. Elsevier, Water Research 121 : pp 248 - 257.

15. Setiyanto, I., \& Hartoko, D. A (2006). Uji Daya Apung Bahan Polyurethane Dan Styrofoam. Jurnal Sanitek Perikanan Vol. 2, No. 1, 2006 : pp $54-58$.

16. Wahyono, H. D., Nugroho, R., Indriatmoko, H., Said, N. I., Yudo, S., \& Sudinda, T. W. (2014). Sistem Pemantauan Online Untuk Pengendalian Pencemaran Kualitas Air di DAS Ciliwung. Jakarta : Pusat Teknologi Lingkungan - BPPT

17. Zhang, D., Sullivan, T., Burghina, C. B., Murphy, K., McGuinness, K., O'Connor, N. E., Smeaton, A., \& Regan, F. (2014). Detection and Classification of Anomalous Events in Water Quality Datasets Within a Smart City - Smart Bay Project. International Journal on Advances in Intelligent Systems, vol 7 no $1 \& 2$ : pp 167-178.

18. Dundjerski, J. J., Savic, R., Grabic, J., \& Blagojevic, B. (2017). Water Quality Trends of the Tisa River Along its Flow Through Serbia. Research Gate Annual Set The Environment Protection, vol 19 Year 2017 : pp 17-35 